\title{
Unrepresentative claims: Refusing to represent as a source of power and legitimacy
}

Samuel Hayat (French National Center for Scientific Research)

First draft, please do not quote (contact the author: samuel.hayat(a)cnrs.fr)

This paper is about situations in which people actively refuse to make representative claims or refute their own representativeness. While they may seem to constitute a minor and borderline case in the study of political representation, taking these claims seriously may help us understand some quite common political interactions that we may not be fully equipped to deal with. Yet among these interactions, some can be said to gain prominence these days, especially when it comes to social movements, and much of my interest for this question was prompted by the French Yellow Vest movement and the difficulties in interpreting it. More importantly, these claims articulate representation and power in a way that seems at odds with how we intuitively think their relation, making them potentially of some interest for our understanding of representation.

First, this paper will start with a discussion of the constructivist turn in the study of political representation, focusing on situations in which you have representation without representative claims, that may prove challenging to analyze. I will show how claims of misrepresentation actually fit quite well in Saward's framework, to the contrary of unrepresentative claims that thus pose specific difficulties. Then I will give examples of unrepresentative claims, in order to inductively uncover some of their characteristics, starting with the Yellow Vest movement and then considering multiple other kind of unrepresentative claims. Finally I will give some provisional and partial elements for a more general theorization of unrepresentative claims.

\section{Representation without representative claims}

\section{Representation after the constructivist turn}

Much of the discussion on political representation has been focused lately on the constructivist turn initiated, at least in Anglo-American political theory, by Michael Saward's famous conceptualization of "representative claims" (Saward 2006; 2010) - and by other endeavors going in the same direction (Rehfeld 2006). Saward makes an argument that is both simple and compelling: representation is fundamentally an activity of claim-making, in which a maker presents an audience with a relation between a subject and an object - the latter being constructed by selecting elements from an existing referent. This groundbreaking work, situated at the crossroads of analytical political theory and structuralist constructivism, has undeniably been extremely influential in the way political representation is conceptualized.

Still, when political theorists have been collectively and individually discussing this framework these past few years, a certain number of problems have progressively appeared. 
Among them, one particularly and repeatedly stroke me: the fact that a lot of political claims that roughly followed the structure of Saward representative claims were made by people who would not call the relations these claims established relations of representation. This proved to be quite a difficulty in a collective French and German research project I was part of, entitled "(New) Political Representative Claims: A Global View (France, Germany, Brazil, China, India)" (CLAIMS). The point of the project was to compare representative claims in different countries, focusing on what we call in France participative devices, i.e. instances of deliberative democracy. When we initially framed this project, we thought that the vocabulary of representation would be pervasive in these forums, maybe because of our previous research, especially Yves Sintomer's work on participatory budgeting in Brazil and mine on the French workers movement - two instances in which representative claims played an important role. This was also aligned with the results of previous investigations on "citizen representatives", a term coined my Mark Warren precisely to emphasize the representative role of citizens in participative and deliberative forums (Warren 2008).

But soon it appeared that in the majority of our case studies, apart from interest groups, most participants to these devices were reluctant to actively claim any form of representativeness. Sure, they did make claims that would entirely integrate into Saward's framework, such as saying (a made example): "As an inhabitant of this neighborhood I contest this policy"; but if asked whether they considered themselves as representatives of the said neighborhood, they would mostly answer by the negative ${ }^{1}$. Here, the structure of the sentence makes the representative claim at stake obvious. But what about the use of the simpler structure "we do not want this policy"? Here there is a claim by an implicit 'I' to represent a 'we', but the composition of the claim is less clear, as the subject, maker, object, referent are all contained in this 'we'. To go one step further, when a participant says "This policy is bad for the neighborhood" or even "This is a bad policy", there is undeniably a subject (the participant), an object (the neighborhood affected by the policy), an audience (the municipal agents, the other participants) and a referent (actual people living in the neighborhood). There is undeniably a claim here, but is it a representative claim per se? And if so, then doesn't it mean that every political statement is a representative claim?

This issue has already been discussed on previous occasions, as it is at the core of the ambiguity of Saward's contribution. On the one hand, it is of tremendous help to denaturalize some inherited assumptions, such as the opposition between representation and participation or the assimilation of representation with democratic elections. On the other hand, it can result in turning every political statement into a representative claim, and every representative claim into a relation of representation, which is in itself both useful in making us grasp the representative nature of politics and detrimental to our ability to demarcate a symbolic space of representation that is not the entire political realm, and the entire social reality even less so. So there is a choice to make between an extensive understanding of Saward's representative claim, where every political statement or even any symbolic act, linguistic or not, relating different elements of the world, is said to be a representative claim; and limited conceptions

\footnotetext{
${ }^{1}$ This point has been previously made by several scholars working on participation, such as Volkan Gül and Louise Knops.
} 
of representative claims, in which you need to actually have someone making an explicit claim $^{2}$.

It may seem obvious that the latter possibility is more desirable (and I think it is): if everything is a representative claim, then nothing is and the constructivist turn puts all our well-crafted analyses about representation at risk. But this leaves a question open: if there is a representative claim only when there is an explicit (or at least an implied) claim to represent, for oneself or for another subject, then what about the political claims that are not representative claims? Do they have nothing to do with representation? If so, isn't there the risk to reintroduce an impenetrable frontier between representation and phenomena such as direct participation - the frontier that was rightfully questioned by the representative turn in democratic theory (Näsström 2011)? And if they have to do with representation, how can we characterize them in a way that do not include them in the too broad category of representative claims in the extended sense?

\section{Claims of misrepresentation}

The point of this paper is to participate in this discussion of representation beyond representative claims or representation without representative claims or non-representative claims. To do that, I start with a marginal situation, one that I have encountered quite often both in my own work on labor movements and in the work of others: cases in which there is an explicit claim to not represent, what I will call here an unrepresentative claim. With this concept that is yet to be constructed properly, I intend to broadly designate the movements and situations in which participants, sometimes even leaders and spokespersons, explicitly refuse to claim they represent anyone but themselves ${ }^{3}$.

At first glance, unrepresentative claims may seem to fit in a larger and better-known category of claims, in which someone refutes an implicit or explicit representative claim. Two members in the collective project I mentioned have coined these "claims of misrepresentation" or "negative claims" (Guasti and Rezende de Almeida 2019). Working with Virginie Dutoya on the representative claims of the French extreme right leader Marine Le Pen, we have ourselves noticed the importance of these claims of misrepresentation in her general rhetorical strategy. These "negative claims" are political claims, they are about

\footnotetext{
${ }^{2}$ This has to be linked with another important dichotomy made by several scholars (Alessandro Mulieri, Thomas Fossen) between radical and moderate constructivism. According to the radical version of Saward's constructivism, the political or even social reality is entirely constructed by these claims: the structure of reality is only defined by the contingent success of the claims. In the moderate version, on the contrary, social reality preexist any claim, so the structure of the referent actually matters when it comes to the success or failure of the claims. This should be related with Pierre Bourdieu's critique of Marxian conception of social classes, Bourdieu advocating against Marx for a radical constructivism by refuting that classes exist as economic realities before they are represented (Bourdieu 1991b). This is a major topic of social history, as testified by the numerous debates around the "linguistic turn" from the 1970s to the 1990s (Stedman Jones 1983; Mayfield and Thorne 1992; Lawrence and Taylor 1993; Sewell 2005). I superficially touched on these questions in (Hayat 2019). For a much more thorough treatment see (Fossen 2019). Also see for a discussion on representation and poststructuralism (Thomassen 2017).

${ }^{3}$ It is still unclear for me at this point whether it should be considered as a proper analytical concept that could be precisely defined (as Saward's) or as an ideal-type loosely and inductively constructed from several otherwise incomparable empirical situations. This first draft tends to the latter option but it may evolve in the future.
} 
representation, but they are not representative claims, as they intend to refute the validity of a claim. So are unrepresentative claims just a form of claims of misrepresentation, in which the makers of the negative claims are the subjects of the positive claims the latter intend to refute? It seems to me that unrepresentative claims are quite distinct from the other claims of misrepresentation. Indeed, claims of misrepresentation share three characteristics that make them fit easily in Saward's framework - that I would contend that unrepresentative claims do not have.

Firstly, claims of misrepresentation often follow an implicit or explicit representative claim, that may concern the institution as a whole or the ability of a given individual to represent the institution ${ }^{4}$. And often, they share the same structure, just with a negative sign in the relation between the subject and the object: a maker puts forward a subject which is said to not stand for an object that is related to a referent and is offered to an audience. The maker can be a member of the audience (or the intended constituency), she can put forward another object (sometimes relating to the same referent) to justify her claim ('S pretends to represent $\mathrm{O}_{1}$ but she actually represents $\mathrm{O}_{2}$ '). All these claims, positive or negative, use a common grammar and participate in a common series of speech acts. Secondly, these claims of misrepresentation generally imply a tension between description and prescription, positive and normative: they make the point that there is a mis-representation, i.e. a defect, a flaw in a given reality: there $i$ s mis-representation where there should be representation, and the point of the claim - even if it is purely rhetoric - is to repair this flawed relation of representation or to replace it with a better one. It means that not only do representative claims and claims of misrepresentation share the same grammar, they often share the same commitment to establishing valid relations of representation. Finally, these claims are often made with the intention to critique an existing representative claim (maybe to establish another one more firmly, but that does not matter here). It means that these negative claims undermine a person or an institution's authority, in order to make away or to counter some of the power they can exert in a given situation. So in a way, these negative claims make sense in the general framework of representative claims: some people make representative claims to justify, legitimize, emphasize, perform or trigger a power relation; other persons resist or refute these claims. To follow Michel Foucault, power goes together with resistance, because exerting power requires the subject of the power relation to collaborate in a way, which she can always refuse (often with consequences), otherwise it is not power, just pure violence (Foucault 1982). By analogy, since a representative claim has to be accepted to result in some gain of power by the subject of the claim, this necessity of acceptance always bears the possibility of refusal. So these negative claims are coherent with a framework in which a successful representative claim leads to a supplement in legitimacy and power. In the political realm, representative claims add to the power of the subject, negative claims or claims of misrepresentation subtract to it. So representative claims and claims of misrepresentation share the same grammar (the 5 roles of Saward), the same objective (establishing relations of

\footnotetext{
${ }^{4}$ Indeed, institutions exist only because there are people who represent them, leading to a constant suspicion that the latter do not properly realize this task - for example, defending their own interest and not the one of the institution they represent. This crucial point, which places misrepresentative claims at the core of the social fabric itself, was made by (Boltanski 2011), who calls this situation "the hermeneutic contradiction". For a discussion of the theoretical implications of the hermeneutic contradiction, see (Blokker 2014; Blokker and Brighenti 2011).
} 
representation) and the same polarity (a representative claim gives power, its contestation withdraws it).

I would argue that unrepresentative claims function very differently. There negative claims do not seem to fit into Saward's framework: they do not participate in debates about contested relations of representation and do not aim to limit the non-representative's power actually quite the contrary. In the unrepresentative claims I want to discuss and understand, negative claims do not precede and prepare better positive representative claims, they do not try to criticize a lack of representation that should be made up for, they do not undermine the non-representer's authority of legitimacy. To grasp their distinctiveness, we will now turn to actual example of unrepresentative claims, first from the French Yellow Vest movement and then from other situations.

\section{Empirical examples of unrepresentative claims}

\section{The unrepresentative claims of the Yellow Vests}

The French Yellow Vest movement is a good starting point because the popularity of the movement, its non-partisan aspect and its apparent initial disorganization led to a real eagerness to appropriate it, from both traditional authorities and from outsiders - leading to multiple representative claims, claims of misrepresentation and, strangely enough, unrepresentative claims. This movement started in November 2018 to protest against taxes on gas, but soon expanded into a more general protest, quite unprecedented in its scope, longevity, diversity, popular support - and in the violence of the repression protestors had to face. Among the movement, the refusal of representative claims was prominent, both against Yellow Vests attempting to speak for the movement, and against institutionalized representatives, be them professional politicians, journalists or trade-union leaders. This attitude towards representation was put to the test several times. As it happened, there was an election to the European Parliament in May 2020, and during the campaign not only did party candidates court the Yellow Vest, several figures of the Yellow Vests themselves stood in the election. There even were two lists that claimed to represent the movement: Alliance Jaune, led by the singer Francis Lalanne and Évolution Citoyenne. They utterly failed to take advantage from the popularity of the movement, obtaining respectively $0,54 \%$ and $0,01 \%$ of the votes. Other attempts were met with strong resistance from Gilets Jaunes, such as the short-lived candidacy of Ingrid Levavasseur, a nursing assistant and one of the movement's early prominent figure. After Levavasseur created a party, the Ralliement d'Initiative Citoyenne $^{5}$, and declared her intention to run for European deputy, she became the target of a large campaign from Yellow Vests, with petitions demanding her to withdraw her candidacy or at least to stop calling herself a Gilet Jaune ${ }^{6}$. She even had to face violent (and misogynic) contestation in the streets by some Yellow Vests, to the point of forcing her out of the weekly demonstrations. She soon gave up and withdrew from the movement. So, in these attempts,

\footnotetext{
${ }^{5}$ A direct reference to the "Référendum d'initiative citoyenne" (RIC), i.e. citizens' initative, which became from December 2018 the main demand of the movement

${ }^{6}$ https://www.mesopinions.com/petition/victoire/retrait-nom-gilets-jaunes-liste-mme/58898
} 
the situation was clear: candidates claiming to represent the Gilets Jaunes met with resistance under the form of claims of misrepresentation.

However, not all attempts to engage in politics faced the same kind of protest. One particular Yellow Vest leader, the commercial executive Benjamin Cauchy, who decided to run for European deputy on a right-wing souverainiste list, took a very different stance. When he rallied behind the chief candidate in April 209, he said "Je ne représente que moi-même" ("I do not represent anyone but myself"). Clearly, it was a negative claim, and as other claims of misrepresentation, it was a reply to a preceding implicit claim: that Benjamin Cauchy actually represented Gilets Jaunes. But if we look at it more closely, it functions very differently from the negative claims mentioned above. First, it does not share the same grammar as positive claims: it is purely negative, there is no object or referent, only the sheer refutation of any relation of representation that may link Cauchy with anyone but himself. Still, this claim is entirely linked with representation, since he makes it to declare his candidacy: representing "just himself" means something more than a mere non-representation, or more precisely this absence of representativeness gives him another kind of representativeness that needs to be defined. The objective of the claim is also much less clear than the usual claims of misrepresentation: it does not aim to establish or contest any significant relation of representation, since no one pretended that Cauchy represented anyone but himself before he claimed it. Yet he was not solely stating the obvious, otherwise his claim would not make any sense. Finally, this unrepresentative claim did not follow the usual correspondence between representation and power. Strangely enough, claiming not to represent was supposed to empower him. Cauchy seemed to think he was more likely to become elected as a representative if he claimed that he represented no one but himself. The difference with usual negative claims does not solely come from the fact that he himself, as a maker, admits his own unrepresentativeness. This rhetoric is quite common: a trade union deploring it is not representative enough (because of a drop in membership, for example), an administration recognizing it is not representative enough from a descriptive perspective, an assembly of activist students postponing a decision because it is not representative enough of the student community and thus calling for a new assembly, and so on. In these cases, a potential representative makes an unrepresentative claim, but presents it as a flaw, a defect that should be corrected. On the contrary, Cauchy's claimed unrepresentativeness seems to be a quality, to the point of a paradox: if he represented anyone but himself, then why him? Why should he be on the list, let alone being elected?

Far from being an isolated case, the phrase "I do not represent" or other approaching ones were repeatedly pronounced by many Gilets Jaunes leaders in different situations. Another early Gilets Jaunes leader, the hypnotherapist Jacline Mouraud, created her own political party in April 2019, but invited on the radio, she claimed: "I represent only myself"7. A group of Yellow Vests started a meeting in December 2018 saying "We are apolitical. We do not represent the Gilets jaunes" 8 ". In February, the truck-driver Eric Drouet, one of the two persons who started the movement, claimed to have "no organizing or leading role in this

\footnotetext{
${ }^{7}$ https://youtu.be/hd9Eb92DrBw

${ }^{8} \mathrm{https}$ ://www.lepopulaire.fr/limoges-87000/actualites/une-reunion-de-gilets-jaunes-avec-des-politiques-dehaute-vienne-ecourtee-apres-des-violences-avec-d-autres-gilets-jaunes_13080099/
} 
movement" but to be a mere "relay"." The other initiator, Pricillia Ludosky, recognized that "some people have the need for representation" but insisted that "among the "figures", as they say, there is not this need (...). I do not have the responsibility to speak in the name of someone in particular ${ }^{10}$." Other occurrences may be found in the discourse of all prominent figures of the movement ${ }^{11}$. More importantly, these strange unrepresentative claims were much better accepted by actual Yellow Vests than the more usual representative claims made by Levavasseur and others. The rhetoric of unrepresentative claims was paradoxically common among Yellow Vest leaders that actually remained in charge - as if it was a necessity to make an unrepresentative claim to remain a representative of the Yellow Vests. In the early days of the movement, a list of 8 spokespersons emerged, selected mostly by cooptation, but they insisted they were only "messengers" and the group lasted only a few days. As Eric Drouet then explained, "there can be no representative for the movement, it is the whole of the Gilets Jaunes that must speak ${ }^{12 " .}$

This refusal to play the game of representation was aligned with some of the movement's prominent features, such as its attachment to a fairly horizontal and democratic form of organization. The Yellow Vests valued the direct expression of citizenship, not necessarily because of an attachment to direct democracy, but to achieve a few things. First, they intended to present themselves as simple citizens addressing the government: the movement was even initiated by a petition to the Minister of Ecology, a traditional way for citizens to express their contempt and wishes. Second, while this was not part of the original protest, they soon mounted a radical critique of the institutions of representative government, perceived as giving power to an incompetent, partial and self-serving oligarchy, a critique that made them extremely sensitive to all forms of appropriation of the movement both by established political leaders or by prominent Gilets Jaunes. Third, the refusal of representation went with a fear for internal division: as the movement gathered people coming from the whole political spectrum, they valued unity to the point of actively avoiding any divisive issue (such as immigration, unemployment or the European Union) in their debates, and one can imagine than competition between potential representatives would have led to division. So refusing representation made sense for Yellow vests, and it obviously implied making unrepresentative claims from time to time. Yet this is not the whole story, because despite all this refusal of representation, leaders emerged. And those who did and managed to stay seemed to be the ones who were the more likely to make unrepresentative claims. Unrepresentative claims were not only ways to be coherent with the Yellow Vests' critique of representation; it also, under some conditions, led to power, legitimacy, and ultimately to representative positions.

\section{Varieties of unrepresentative claims}

\footnotetext{
${ }^{9}$ https://www.lemonde.fr/societe/article/2019/03/30/gilets-jaunes-ces-leaders-qui-refusent-de-letre 5443432 3224.html

${ }^{10} \mathrm{https}$ ://lvsl.fr/priscillia-ludosky-les-gilets-jaunes-ont-mis-un-coup-de-pied-dans-la-fourmiliere/

${ }_{11} \mathrm{https} / / / \mathrm{www} .20$ minutes.fr/societe/2381819-20181127-gilets-jaunes-bretagne-porte-parole-maxime-nicolle https://www.francebleu.fr/infos/societe/gilets-jaunes-deux-des-huit-porte-parole-officiels-sont-franciliens$\underline{1543241669}$
}

Panel: Power, inequalities and representation 
The Yellow Vest movements gave way to numerous interpretations underlining its unprecedented relation to democracy - sometimes including it in the short sequence of radical democratic upheavals that started in 2011. While this may be true of other aspects of the movement, its use of unrepresentative claims is far from unique in the political realm. We mentioned earlier citizens in participative assemblies. Other examples could be found in institutions of international governance, such as multi-stakeholder processes. The one that was set up to draft the norm ISO 26000 (the International Organization for Standardization standard for social responsibility), issued in 2010, was particularly illustrative in that regard (Ruwet 2010; Hahn and Weidtmann 2016). Confronted with critiques for its lack of representativeness and legitimacy, combined with a constant extension of its area of expertise, the ISO then experimented an unprecedentedly open drafting process. Different categories of stakeholders were selected, and for each category representative organizations had to nominate experts. But these experts themselves were not considered as representatives: once selected, they had no mandate and had to express their own perspective, in a deliberative manner, on the discussed matter. The important point here is that not being representatives did not mean for them to express their personal preferences: they could be unrepresentative yet legitimate because they were experts. The combination between nomination and independence was the key here. Could it be said to be equivalent to the position of the Burkean trustee? In his famous speech to the electors of Bristol, Edmund Burke asserted that he should not be bound by any mandate while he served, because

"Parliament is not a congress of ambassadors from different and hostile interests; which
interests each must maintain, as an agent and advocate, against other agents and advocates; but
parliament is a deliberative assembly of one nation, with one interest, that of the whole; where,
not local purposes, not local prejudices, ought to guide, but the general good, resulting from
the general reason of the whole. You choose a member indeed; but when you have chosen
him, he is not member of Bristol, but he is a member of parliament."

However, this is undeniably a relation of representation, in which the representative serves the represented and their interest - even if, to do so, he has to remain independent from their immediate wishes. In the case of ISO 26000, on the contrary, "the experts act in a personal capacity and not as the official representative of (...) organization by which they have been appointed"13: once they are chosen, they are not supposed to act for or stand for the organization that nominated them, but to offer their personal perspective to the deliberation. If one considers solely the mode of delegation, characterized by selection (Mansbridge 2009), they could be said to fall under the category of gyroscopic representation (Mansbridge 2003), i.e. representatives that are selected for their personal characteristics (in particular moral values) and then expected to act accordingly to these. In Andrew Rehfeld's terms, they are indeed self-reliant in their judgments and not responsive to sanctions, thus they should be considered as "Burkean Trustees" or "Volunteers" depending on the kind of aim they follow (Rehfeld 2009). But if we use the framework of representative claims, we may see a huge gap appear: Mansbridge and Rehfeld, as Burke, mostly talk about elected representatives, whose position is the result of a successful representative claim. On the contrary, experts participating in the ISO 26000 committees are... experts, which implies that even if they were selected by stakeholders, they have to claim that themselves have no stake to hold, no interest

${ }^{13}$ ISO/IEC Directives, Part 1, Edition 12.0 2016-05, p. 17. 
to defend, in short that they are not representatives of anything but themselves - in their capacity as experts.

It is not solely a matter of expertise and impartiality, though. In most interest groups and lobbies, representatives are obviously supposed to defend the interests of their employers. Yet, you can sometimes find in these organizations institutionalized forms of unrepresentative claims. It is customary, for example, in French employers' organizations, to have a double head: an elected official, which is often the public face of the organization and should accordingly display the needed characteristics to represent descriptively or symbolically the members of his trade; and an administrator, called "general delegate", who today is always selected from outside the trade, often a former civil servant. The latter's unrepresentativeness is considered an asset, as a good general delegate should be a good servant, and to be a good servant she or he needs to be seen as exterior to the group (Courty, TPB). Because he represents nothing except the group, he can represent the group in all its generality. This is a case in point of Bourdieu's analysis of the role of "oblates" in organizations:

"The institution gives everything, starting with power over the institution, to those who have given everything to the institution. but this is because they were nothing outside the institution or without the institution and because they cannot deny the institution without purely and simply denying themselves by depriving themselves of everything that they have become through and for the institution to which they owe everything." (Bourdieu 1991a, 195)

When a person fully embodies and institution, is this a representative or an unrepresentative claim? In a way, it is both: the oblate embodies the institution, to the point he cannot represent any specific position, interest or group of members in the institution. The total representative claim comes together with a universal unrepresentative claim when it comes to anything else than the whole institution.

A related situation emerges every time a professional is defined by the generality of the interest or principle he defends, which prevents him from making any other representative claim. The archetypical example would be the situation of a judge, who represents the Law and thus cannot claim to represent anything else than the law - and relatedly can claim not to represent anything else, giving him a "legitimacy of impartiality (Rosanvallon 2011) ${ }^{14}$. A similar point could be made about the institutions of the European Union: it is not uncommon for persons who work in Brussels to move from positions in lobbying to positions in the European institutions themselves and vice-versa. The ability to represent an interest in the "field of Eurocracy" is sometimes paradoxically better ensured by a form of professional detachment from it. More importantly, very few agents specifically defend the interest of the Union as a whole. The general interest of the European Union then appears more as a sort of emergent property of the uncoordinated activity of representatives of different interests acting at the European level, representatives that would most likely deny representing "Europe" against State members, for example (Georgakakis 2012; Laurens 2015).

\footnotetext{
${ }^{14}$ According to Rosanvallon, judges (especially those acting in supreme courts) are more adequately characterized in democracies by a "legitimacy of reflexivity": they also represent the people by representing the (popular) constituent or legal principles and deliberating of their adequate legal interpretations. See also (Ackerman 1993). Rosanvallon's developments on "the importance of not being elected" in dualist democracies, while not directly addressing the issue of claim-making, back these remarks.
} 
Going to the other side of the political and institutional spectrum, unrepresentative claims is quite common among activists, not only Yellow Vests. While the labor, feminist or Civil Rights movement all relied on an extensive use of representative claims, more recent popular movements have taken a very different stance. Black feminist movements, maybe because they were born from a reflection on representation and the silencing of the voices of Black women both in feminist and in Black movements, developed distinctive unrepresentative claims, insisting on the importance for people suffering from oppression to speak for themselves. In the preface of Black Feminist Tought, Patricia Hill Collins asked herself "How can I as one person speak for such a large and complex group as African-American woman?", and the answer was a clear unrepresentative claim: "I cannot and should not because each of us must learn to speak for helself", her book being "on voice in a dialogue among people who have been silenced" (Collins 2002, IX). This insistence on not speaking for oppressed groups could also be found, although quite differently, in the Occupy movement. As an article from The Occupied Times explained in 2011, "we do not 'speak for' the poor and oppressed around the world, but we are in solidarity with them ${ }^{15}$ ". Most certainly, there is a representative claim at work when constituting the "We" of the movement, and the "We are the $99 \%$ " should be understood as a proper representative claim. But once the subject "We" is established, the necessity to claim that "We" do not represent but are is not self-evident, as it contradicts a long tradition of social movements. Interestingly enough, the authors of the article link this refusal of representation with Zapatismo. Indeed, its leader, the Subcomandante Marcos, has developed a distinctive relation to representation, both in his writings and in this public stance. He calls himself "subcommander" because the commander is the indigenous people he serves, he uses a nickname, sometimes changing it - he now calls himself "Subcomandante Galeano", the name of a lost friend -, has referred to himself as "Delegate Zero" or as being a "Hologram", he constantly wears a mask when he speaks... His will not to represent, which comes together with a theorization of his own position as not being one of representation, has been deemed "post-representative" and is most certainly at odds with most revolutionary traditions - not only Leninist vanguardism, but also with anarchism (Tormey 2006). Certainly, such unrepresentative claims could be in found in past social movements in which there was a desire to lessen the importance of individuals in favor of the collective. In the early $19^{\text {th }}$ century, in the emerging labor and feminist movements in France, it was customary to use nicknames and to publish articles anonymously or signed collectively, and not only for security reasons - workers writing in L'Atelier and women in La Tribune des femmes explicitly refused the individualization of their political struggle that went with nominal signatures. Similarly, in the Notre-Dame-des-Landes "Zone to Defend" - a movement against the construction of an airport in the west of France that started in 2009 and soon became a junction point for the French and European radical Left - every person that was interviewed by the media or spoke publicly presented him or herself as "Camille". But while in the latter cases unrepresentative claims went together with an effectively collective empowerment, in the case of Marcos his unrepresentative claim seems to give him personal power, or at least not to deprive him of it. Judges, European Commission officials, Camille, Benjamin Cauchy and Subcomandante Marcos may all claim they speak and act on their own behalf and refuse to be considered representatives, it has very different consequences in each of the situations.

$\overline{{ }^{15} \text { https://theoccupiedtimes.org/?p=1054 }}$ 


\section{Elements for a theory of unrepresentative claims}

The diversity of these situations and the kinds of power relations they are built on makes any synthesis tentative at best. Yet it is possible to find some common points to all these claims. In all these configurations, there are claim-makers who explicitly or because of their institutional position refuse that a subject (themselves or a group they are part of) speak in the name of any object other than the subject itself. The object of the claim is thus related to a void referent, or more precisely eliminates all possible referents except the actual real-life person or group of persons constituting the subject. These are claims of misrepresentation of a specific kind, as they concern all possible objects (at least in their purest occurrences) and misrepresentation is not presented as a defect or a fault, but as a desirable feature of the relation, actually giving power to the non-representative subject. Yet in all these situations, the non-representatives are also potentially representatives, either because they are the subjects of other representative claims (such as the citizen representatives who may make unrepresentative claims but have been selected by authorities to constitute a representative mini-public) or because they would be expected to make representative claims since they act as leaders, stakeholders, lobbyists, spokespersons and even candidates to an election. They speak only in their own name, but their unrepresentative claims do not forbid any relation of representation, quite the contrary. Which leads to the question: what does one represent when representing only himself or herself?

The examples given above indicate that there is no univocal answer to this question. The reason for that is that speaking for oneself does not eliminate the question of what this person is speaking as (Fossen 2019). On the contrary, the refusal to represent someone else opens all kind of strategies in which subjects may put forward selected aspects of their self different objects in the sense of Saward. The inherent plurality of personal identities entails that unrepresentative claims always go together with implicit or explicit claims concerning the capacity in which one speaks. This explains why unrepresentative claims may confer power to their subject: by discounting all possible identities that would be given by relations of representation, unrepresentative claims may be used to reinforce the aspect of the subject's identity the maker wants to put forward.

While it would be impossible to list all the identities that could be represented when one refuses to represent anything else but oneself, previous examples give us some directions. First, at the most abstract level, unrepresentative claims may reinforce one's claim to speak as an unattached individual, guided purely by her reason, or possibly by a principle she may embody: justice (judges), the general interest (Rousseau's legislator), the people's true original will (members of the Supreme Court). When Yellow Vest leaders speak as simple citizens, they emphasize the generality of their position, render them utterly representative, since they claim they could be any citizen. Second, unrepresentative claims may allow individuals to claim to be fully defined by one past or present affiliation; they can be experts, permanents of an organization, spokespersons for a movement. Yellow Vests leaders claiming to be just simple Yellow Vests belong to this category, with the same consequences as above: pretending to be a Yellow Vest with no other characteristic, it is as if they had been selected at random, enabling them to speak for the whole movement. Finally, subjects of 
unrepresentative claims may wish to put forward a specific part of their social identity: being a member of a social group, having given characteristics or experience.

In all three cases, agents claim to be able to speak as members of a general entity, an organization or a social group precisely because they cannot speak for them, not having been authorized to do so. We recognize here the logics of representation as embodiment, the repraesentatio identitatis that has been uncovered by Hasso Hoffman and recently discussed by Alessando Mulieri or Yves Sintomer (Hofmann 1973; Mulieri 2014; Sintomer 2018). The representative does not hold a mandate, he is a pars pro toto, a part of a group speaking for the whole. The ubiquity of unrepresentative claims shows that far from being remains of medieval times, occurrences of representation as embodiment are still part of the rhetoric of multiple agents and institutions ${ }^{16}$. It also emphasize the opposition between mandate and embodiment: in a way, asserting that one does not hold a mandate may in some cases be mandatory to successfully claim to embody a group. Not only does speaking as a member of a group may be compatible with claiming not to speak for the group, it sometimes goes together. In the case of Patricia Hill Collins, the unrepresentative claim by which she refused to speak for Black women is what allowed her to speak as a Black woman without betraying the identity she claimed to represent. To embody the Yellow Vest movements, its leaders had to deny any form of mandate that would have separated them from the rest of the Yellow Vests, thus preventing them to claim to be one of them.

This kind of embodiment through unrepresentative claim seems of particular importance in situations where there are no mandates (which often means no centralized organization). Then being recognized as (a) representative of a group often implies being selected to play the part of the member of the group in narratives that need embodiment to describe a reality. Most Yellow Vests figures emerged because they were available and competent enough to play the role of a Yellow Vest in TV shows. While they refused to represent the Yellow Vests in the usual sense of political representation, they represented them from an aesthetic point of view, as past characters in historical narratives (Ankersmit 2001; 2002). This goes together with an absence of accountability: since there is no mandate and the selection of representatives is entirely based on their harmony with a narrative, they are not subjected to control by possible represented agents. This is another reason why unrepresentative claims can actually empower their subjects: claiming to not represent is a way for a leader not to be held accountable for her action. When asked why he intended to participate in the summer camp of La France insoumise, a left wing populist party, the Yellow Vest leader Jérôme Rodrigues answered:

"Today the Yellow Vest movement does not wish to have leaders, representatives or even heads, something I agree with, so I am not at all this person, I am part of the movement as anyone, and present since the beginning. As a result I have no nominative legitimacy that could prevent me from speaking and debating with anyone I want. I had the occasion these past few months to discuss, exchange views and debate with all the groups and trends representing the Yellow Vests movement in France. From all the claims, one emerges,

\footnotetext{
${ }^{16}$ It does not mean that unrepresentative claims and embodiment necessarily go together: many forms of embodiment rely on explicit representative claims.
} 
'freedom'... this freedom of expression I would like to enjoy and thus discuss with those who invited $\mathrm{me}^{17}$."

In this Facebook post, Rodrigues explicitly made an unrepresentative claim, which allowed him to claim at the same time that he belonged to the movement, that he was free from any mandate and accountable to no one, and that this freedom was aligned with the ultimate spirit of the movement. In a political world where being a representative means being accountable to the represented, making unrepresentative claims is a way to declare oneself free from any check or control, while still embodying the represented and thus benefiting from the power given by the status of being a representative.

\section{Conclusion}

Unrepresentative claims are claims of a specific kind. As in other negative representative claims, makers deny the existence of a relation of representation. But this nonrepresentativeness paradoxically empowers the subjects: successful unrepresentative claims allows subjects to put forward their affiliation to an aspect of their identity and thus to embody it, while remaining free of any control for potential representatives. Should we then say they are a particular case of representative claims, only distinctive in their rhetoric? It may well be the case, especially if we consider examples such as the Yellow Vest movements, among which unrepresentative claims are pervasive, especially when it comes to their leaders. Ultimately, their political power comes from the fact that they can act and speak as representatives of the movement. Still, the fact than they obtain this status and power from unrepresentative claims turn them into representatives of a specific kind, articulating representation and power in a way that is at odds with more traditional relations of representation. Maybe this can help enrich our understanding of political representation, especially when it comes to its non electoral forms, which are bound to flourish in a political world where States lose their centrality.

\section{References}

Ackerman, Bruce. 1993. We the People, Volume 1: Foundations. Cambridge: Belknap Press of Harvard University Press.

Ankersmit, Franklin Rudolf. 2001. Historical Representation. Stanford University Press. . 2002. Political Representation. Stanford (Calif.): Stanford university press.

Blokker, Paul. 2014. "Luc Boltanski and Democratic Theory: Fragility, Auto-Nomos, and Critique as Democracy's End." Thesis Eleven 124 (1): 53-70.

Blokker, Paul, and Andrea Brighenti. 2011. "Politics between Justification and Defiance." European Journal of Social Theory 14 (3): 283-300.

Boltanski, Luc. 2011. On critique: a sociology of emancipation. Cambridge, UK; Malden, MA: Polity.

Bourdieu, Pierre. 1991a. "Political Representation: Elements for a Theory of the Political Field.” In Language and Symbolic Power, edited by John B Thompson, 171-202. Cambridge, Mass.: Harvard University Press.

17 https://www.facebook.com/lafamillejerome/posts/394166784574811? tn $=\mathrm{K}-\mathrm{R}$ 
. 1991b. "Social Space and the Genesis of 'classes"." In Language and Symbolic Power, edited by John B Thompson, 229-51. Cambridge, Mass.: Harvard University Press.

Collins, Patricia Hill. 2002. Black Feminist Thought: Knowledge, Consciousness, and the Politics of Empowerment. London: Routledge.

Fossen, Thomas. 2019. "Constructivism and the Logic of Political Representation." American Political Science Review 113 (3): 824-37.

Foucault, Michel. 1982. "The Subject and Power." Critical Inquiry 8 (4): 777-95.

Georgakakis, Didier, ed. 2012. Le champ de l'Eurocratie. Une sociologique politique du personnel de l'UE. Paris: Economica.

Guasti, Petra, and Debora Rezende de Almeida. 2019. "Claims of Misrepresentation: A Comparison of Germany and Brazil." Politics and Governance 7 (3).

Hahn, Rüdiger, and Christian Weidtmann. 2016. "Transnational Governance, Deliberative Democracy, and the Legitimacy of ISO 26000: Analyzing the Case of a Global Multistakeholder Process." Business \& Society 55 (1): 90-129.

Hayat, Samuel. 2019. "Representation as Proposition: Democratic Representation after the Constructivist Turn." In The Constructivist Turn in Political Representation, edited by Nadia Urbinati, Lisa Disch, and Mathjis van de Sande. Edimburg: Edimburg University Press.

Hofmann, Hasso. 1973. Repräsentation: Studien zur Wort- und Begriffsgeschichte von der Antike bis ins 19. Jahrhundert. Schriften zur Verfassungsgeschichte. Berlin: Duncker \& Humblot.

Laurens, Sylvain. 2015. Les courtiers du capitalisme: Milieux d'affaires et bureaucrates à Bruxelles. Marseille: Agone.

Lawrence, Jon, and Miles Taylor. 1993. "The Poverty of Protest: Gareth Stedman Jones and the Politics of Language - a Reply." Social History 18 (1): 1-15.

Mansbridge, Jane. 2003. "Rethinking Representation." American Political Science Review 97 (4): 515-28.

. 2009. “A 'Selection Model' of Political Representation*.” Journal of Political Philosophy 17 (4): 369-98.

Mayfield, David, and Susan Thorne. 1992. "Social History and Its Discontents: Gareth Stedman Jones and the Politics of Language." Social History 17 (2): 165-88.

Mulieri, Alessandro. 2014. "Political Representation: A Historical and Conceptual Investigation into Its Polysemy." KU Leuven.

Näsström, Sofia. 2011. "Where Is the Representative Turn Going?:” European Journal of Political Theory, October. https://doi.org/10.1177/1474885111417783.

Rehfeld, Andrew. 2006. “Towards a General Theory of Political Representation." Journal of Politics 68 (1): 1-21. 2009. "Representation Rethought: On Trustees, Delegates, and Gyroscopes in the Study of Political Representation and Democracy." American Political Science Review 103 (02): 214-230.

Rosanvallon, Pierre. 2011. Democratic Legitimacy Impartiality, Reflexivity, Proximity. Princeton: Princeton University Press.

Ruwet, Coline. 2010. "Que représentent les stakeholders ? Le cas de l'élaboration d'ISO 26000." Revue française de science politique 60 (6): 1115-35.

Saward, Michael. 2006. "The Representative Claim." Contemporary Political Theory 5 (3): 297-318.

. 2010. The representative claim. Oxford: Oxford University Press. 
Sewell, William H. 2005. Logics of History: Social Theory and Social Transformation. Chicago: University Of Chicago Press.

Sintomer, Yves. 2018. "La représentation-incarnation : idéaltype et configurations historiques." Raisons politiques, no. 72: 21-52.

Stedman Jones, Gareth. 1983. Languages of Class: Studies in English Working Class History 1832-1982. Cambridge: Cambridge University Press.

Thomassen, Lasse. 2017. "Poststructuralism and Representation." Political Studies Review 15 (4): 539-50.

Tormey, Simon. 2006. “"Not in My Name': Deleuze, Zapatismo and the Critique of Representation.” Parliamentary Affairs 59 (1): 138-54.

Warren, Mark E. 2008. "Citizen Representatives.” In Designing Deliberative Democracy: The British Columbia Citizens' Assembly, by Mark E. Warren and Hilary Pearse, 50-69. Cambridge: Cambridge University Press. 